08

\title{
Некоторые особенности конденсации атомов кремния на поверхности монокристалла вольфрама
}

\author{
() О.Л. Голубев \\ Физико-технический институт им. А.Ф. Иофрфе РАН, \\ 194021 Санкт-Петербург, Россия \\ e-mail: O.Golubev@mail.ioffe.ru
}

Поступило в Редакцию 25 июля 2019 г.

В окончательной редакции 25 июля 2019 г.

Принято к публикации 16 сентября 2019 г.

$\mathrm{C}$ помощью методов полевой эмиссионной микроскопии изучена конденсация $\mathrm{Si}$ на поверхности $\mathrm{W}$ при различных температурах подложки $T$ и количествах $n$ моноатомных слоев осажденного конденсата. При низких $T \sim 600 \mathrm{~K}$ на поверхности формируется низкотемпературный монослой $\mathrm{Si}$ со структурой чистого $\mathrm{W}$, тогда как при $T \geq 1000 \mathrm{~K}$ формируется другая структура высокотемпературного монослоя или поверхностного силицида. Низкотемпературный монослой и поверхностный силицид различаются также и ориентирующим действием при наращивании слоев $\mathrm{Si}$. В случае конденсации на низкотемпературный монослой собственные кристаллиты $\mathrm{Si}$ формируются уже начиная с третьего монослоя $n \geq 3$, тогда как при конденсации на поверхностный силицид рост кристаллитов $\mathrm{Si}$ происходит начиная с $n \geq 300$ монослоев. Определены величины энергий активации $Q_{\text {dif }}$ объемной диффузии $\mathrm{Si}$ в объем W и энергии десорбции $Q_{\mathrm{des}}$ атомов Si с поверхности W.

Ключевые слова: кремний, вольфрам, адсорбция, моноатомный слой.

DOI: $10.21883 /$ JTF.2020.03.48933.283-19

\section{Введение}

Исследование адсорбции кремния на поверхности вольфрама и происходящие при этом структурные формоизменения являются важным аспектом современной физики поверхности и эмиссионной электроники со многих точек зрения. Подобного рода исследованиям было посвящено достаточно много работ с использованием разных методик, например $[1,2]$, и в том числе с использованием полевых эмиссионных методов [3-5], методы эти дают определенные преимущества за счет своей специфики - прежде всего высокого пространственного разрешения и возможности работать при любых $T$ образца от криогенных до близких к $T$ плавления. Однако работы эти касались в основном адсорбции и миграции одиночных атомов $\mathrm{Si}$ и определения энергий активации для миграции адсорбированных атомов (адатомов) Si на отдельных гранях различных металлов, либо изучению начальных стадий образования объемных силицидов разных металлов. Следует отметить, что в последнее время большой интерес проявляется к изучению формирования на поверхности металлов и соединений так называемых силиценов - моноатомных слоев со структурой типа графена, однако в этих экспериментах вольфрамовые подложки как правило не используются $[6,7]$.

При этом неизученным оставались вопросы закономерностей кристаллического роста пленок самого $\mathrm{Si}$ на поверхности металлов при широкой вариации количества моноатомных слоев (монослоев) n-сконденсированного адсорбата и при значительном изменении температуры подложки $T_{s}$. Подобного рода исследования могут, во-первых, позволить выявить интересные закономерности кристаллического роста, а во-вторых, прояснить проблемы создания на поверхности металлов точечных источников электронов и ионов, состоящих как из самого кремния, так и из силицидов металлов. Кроме того, подобные исследования могут представить интерес для проблемы формирования таких точечных источников электронов и ионов, которые могут образовываться по поверхности $\mathrm{W}$ при одновременном воздействии высоких $T$ и сильных электрических полей $F$ на слои кремниевого адсорбата на W [8]. Таким образом, целью настоящей работы было изучение структурных формоизменений слоев $\mathrm{Si}$ на $\mathrm{W}$ и термической стабильности данных слоев при широкой вариации количества сконденсированного материала и температуры подложки.

\section{1. Методика и техника эксперимента}

Основные эксперименты, результаты которых представлены в настоящей работе, были выполнены с помощью методов полевой эмиссионной микроскопии при конденсации Si на W, ряд экспериментов был проведен с эмиттерами-подложками из Ir и Re, которые дали схожие результаты и здесь рассматриваться не будут. Монокристаллические острия с радиусом кривизны в доли микрон получались методом обычного электролитического травления. Получение слоев атомарно чистого $\mathrm{Si}$ на поверхности представляет собой 
довольно сложную задачу, поскольку $\mathrm{Si}$ обладает все же невысокой температурой плавления $T=1680 \mathrm{~K}$, но при этом имеет достаточно значительную теплоту испарения $\lambda_{0}=4.5-4.9 \mathrm{eV}$. Для получения достаточно больших потоков атомов $\mathrm{Si}$ предпочтительно осуществлять конденсацию из жидкой фазы, нагревая $\mathrm{Si}$ выше $T$ плавления. Однако в этом случае приходится использовать тигли и при этом очень трудно обеспечить атомарную чистоту покрытия. В нашем случае источником Si служила накаливаемая током кремниевая пластина высокой чистоты с удельным сопротивлением $\rho=10^{-2} \Omega \cdot \mathrm{cm}$, легированная сурьмой с концентрацией $10^{17} \mathrm{at} / \mathrm{cm}^{2}$. Концентрация легирующего элемента ничтожно мала $\sim 10^{-3} \%$, однако если теплота испарения $\mathrm{Sb}$ из матрицы $\mathrm{Si}$ меньше собственной теплоты испарения $\mathrm{Si}$, то поток атомов $\mathrm{Sb}$ в принципе может быть значителен. Поэтому для очистки источник $\mathrm{Si}$ тренировался прогревом в высоком вакууме $p=10^{-8}-10^{-9} \mathrm{~Pa}$ в течение $15-20 \mathrm{~h}$ при $T=1500-1600 \mathrm{~K}$. Подобная тренировка обеспечивала полную очистку источника от примесей, как это показал масс-спектрометрический контроль потока атомов $\mathrm{Si}$, осуществленный по методике, описанной в работе [2]. Эксперименты проводились на универсальной высоковакуумной установке, позволявшей совмещать режимы работы полевого электронного, ионного и десорбционного микроскопов [9]. Напряженность электрического поля $F$ и работа выхода $\varphi$ определялись традиционными методами из наклона эмиссионных характеристик Фаулера-Нордгейма [10].

\section{2. Результаты и обсуждение}

\section{1. Домонослойные и монослойные покрытия кремния}

Эксперименты по конденсации $\mathrm{Si}$ на поверхности вольфрамового монокристаллического острия-эмиттера при различных температурах подложки $T_{s}$ и разных, но относительно небольших количествах адсорбата домонослойных и монослойных толщиной $n=0.1-1.5$ моноатомных слоев (монослоев) показали, что при домонослойных и монослойных покрытиях слой адсорбата при разных $T_{s}$ подложки может быть в трех принципиально разных структурных состояниях. При низких температурах $T_{s} \leq 300 \mathrm{~K}$ на поверхности $\mathrm{W}$ формируется неупорядоченный, практически аморфный слой $\mathrm{Si}$, однако рост $T_{s}$ вызывает упорядочение слоя адсорбата и уже при $T_{s}=450-650 \mathrm{~K}$ слой полностью упорядочивается и образуется структура, которую можно назвать „низкотемпературный монослой“. Низкотемпературный монослой является псевдоморфной структурой, которая примерно соответствует структуре поверхности чистого W. Наконец, уже при высоких $T_{s} \geq 1000 \mathrm{~K}$ (начинается этот процесс уже при $700 \mathrm{~K}$ ) образуется характерная структура высокотемпературного монослоя, при этом происходит реконструкция поверхности $\mathrm{W}$, которая выражается в том, что значительно расширяются грани $\{112\}$ и формируются новые грани типа $\{012\}$ вокруг граней куба $\{001\}$, эти грани отсутствуют на поверхности чистого W и низкотемпературного монослоя. Структуру высокотемпературного монослоя можно назвать „поверхностный силицид“, термин этот был введен довольно давно авторами [2], при этом под данным термином понималось состояние геометрического монослоя $\mathrm{Si}$ на поверхности W, которое возникало при концентрации $n=1 \cdot 10^{15} \mathrm{at} / \mathrm{cm}^{2}$ атомов Si на грани $\{100\} \mathrm{W}$, когда на один атом Si приходится один атом W. Нам представляется, что термином поверхностный силицид лучше характеризовать не любой упорядоченный монослой с определенной концентрацией, а монослойное покрытие, связанное с реконструкцией поверхности подложки, что связано, в свою очередь, с химическим взаимодействием атомов адсорбата и атомов поверхности. Полевые электронные изображения поверхности, соответствующие низкотемпературному монослою $\mathrm{Si}$, полученному при $T_{s}=650 \mathrm{~K}$, и поверхностному силициду, который получен при $T_{s}=1200 \mathrm{~K}$, показаны на рис. $1, a, c$ соответственно (рис. 1, $a$ - чистый $\mathrm{W}$ ).

Однако главным различием между низкотемпературным монослоем и поверхностным силицидом является не структурное отличие, а разное ориентирующее действие при наращивании на них новых слоев Si. Если конденсацию Si проводить на поверхность низкотемпературного монослоя, то уже, начиная с небольших покрытий $n \geq 3$, можно наблюдать образование мелких собственных кристаллитов $\mathrm{Si}$. На рис. 2, $a$ показано образование подобных кристаллитов при $n=4$ и $T_{s}=650 \mathrm{~K}$. Если же конденсацию проводить на поверхность, соответствующую поверхностному силициду, то характер ростового процесса совершенно иной. Рис. 2, $b$ демонстрирует полевое электронное изображение поверхности, соответствующие эксперименту, который проводился следующим образом. Вначале при $T_{s}$ острия, равной $1200 \mathrm{~K}$, конденсировался монослой $\mathrm{Si}$ и получался поверхностный силицид, показанный на рис. $1, c$, затем $T_{s}$ острия опускалась до той же $T_{s}=640 \mathrm{~K}$ и производилась конденсация следующих слоев $\mathrm{Si}$. Видно, что даже при конденсации 250 монослоев наблюдается поверхностная структура, характерная для поверхностного силицида, и собственные кристаллиты Si не образуются (рис. 2, $b$ ). Только при достижении покрытий $n \sim 300$ монослоев (рис. 2,c) наблюдается образование значительного количества кристаллитов $\mathrm{Si}$ с собственной огранкой. Таким образом, эксперименты, некоторые стадии которых показаны на рис. 2, позволяют сделать вывод, что при конденсации $\mathrm{Si}$ на поверхность низкотемпературного монослоя реализуется механизм роста Странского-Крастанова, когда один (может быть и два) монослоя экранируют влияние подложки, после чего становится возможным рост собственных кристаллитов Si. В случае же конденсации на поверхностный силицид реконструкция создает поверхность, благоприятную для наращивания почти невозмущенных (ненапряженных) слоев $\mathrm{Si}$ с единой цельной структу- 

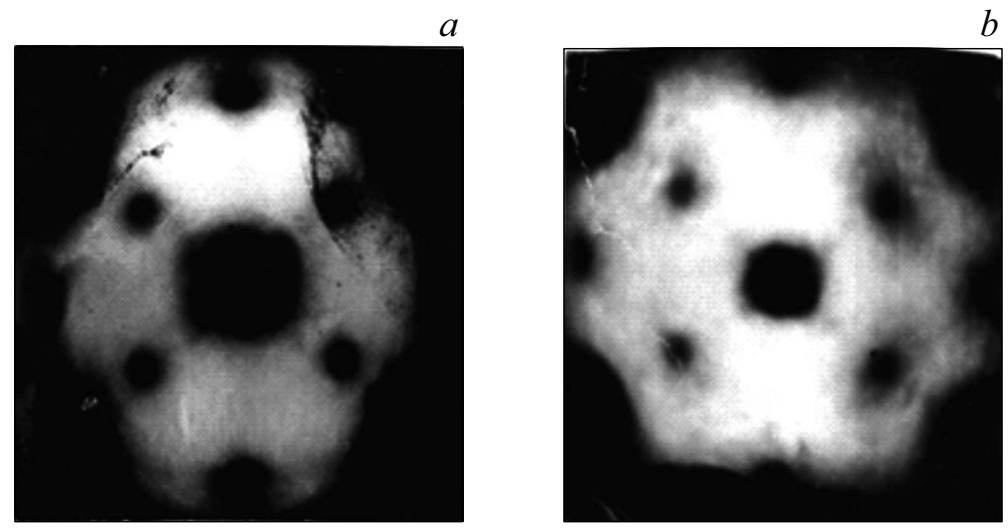

$b$

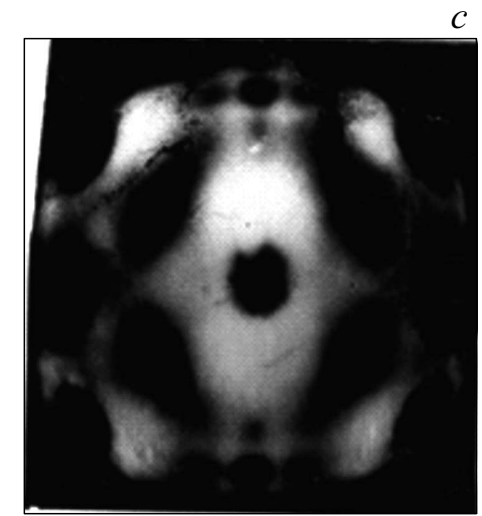

Рис. 1. Полевые электронные изображения поверхности W-эмиттера после конденсации одного моноатомного слоя $\mathrm{Si}$ при различных температурах $T_{s}$ подложки: $a-$ поверхность чистого $\mathrm{W} ; b-$ поверхность после конденсации одного монослоя $\mathrm{Si}$ при $T_{s}=650 \mathrm{~K} ; c-$ после конденсации одного монослоя $\mathrm{Si}$ при $T_{s}=1200 \mathrm{~K}$.

$a$

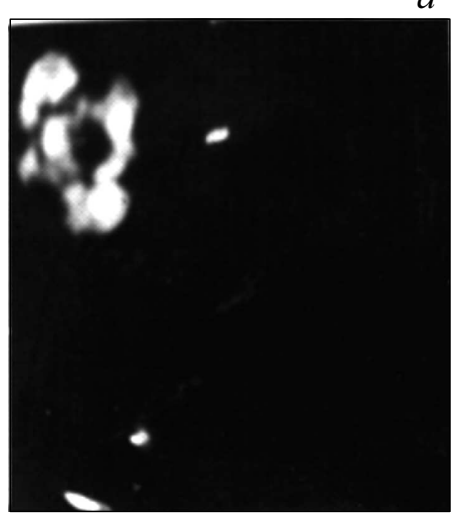

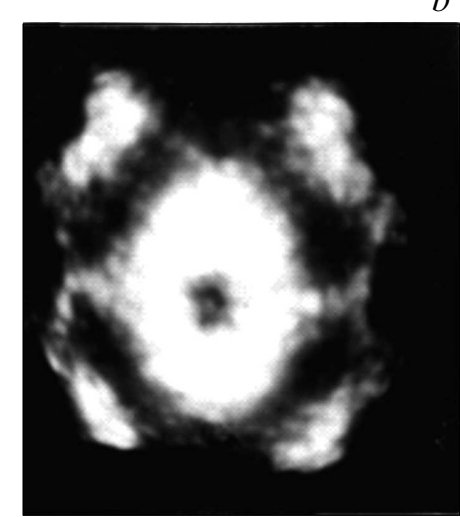

$b$

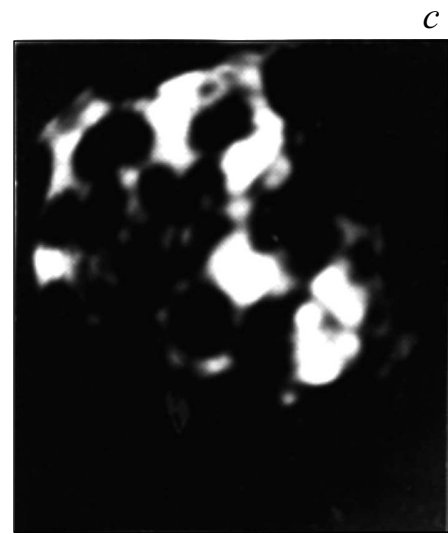

Рис. 2. Полевые электронные изображения поверхности $\mathrm{W}$-эмиттера после конденсации различных количеств $n$ моноатомных слоев $\mathrm{Si}$ при различных температурах $T_{s}$ подложки: $a-$ после конденсации $n=5$ монослоев $\mathrm{Si}$ при $T_{s}=650 \mathrm{~K} ; b-$ после конденсации одного монослоя $\mathrm{Si}$ при $T_{s}=1200 \mathrm{~K}$ и последующей конденсации $n=250$ монослоев $\mathrm{Si}$ при $T_{s}=650 \mathrm{~K} ; c-$ после конденсации одного монослоя $\mathrm{Si}$ при $T_{s}=1200 \mathrm{~K}$ и последующей конденсации $n=300$ монослоев $\mathrm{Si}$ при $T_{s}=650 \mathrm{~K}$.

рой поверхностного силицида. Однако, в конце концов, неполная изоморфность и накапливание структурных несоответствий приводит к формированию собственных кристаллитов Si. Следовательно, в данном случае реализуется механизм роста Франка-Ван дер Мерве. Хотя W и Si неизоморфны, однако реконструкция поверхности $\mathrm{W}$ делает возможным формирование на ней значительного количества (более 200) псевдоморфных слоев как переходной стадии от чистого W к чистому $\mathrm{Si}$ [10]. Низкотемпературный монослой и поверхностный силицид различаются между собой также и по своим электронным свойствам. В случаях осаждения как при $T=650 \mathrm{~K}$, так и при $T=1200 \mathrm{~K}$ адсорбция $\mathrm{Si}$ вызывает плавное повышение средней работы выхода вольфрама $\varphi$, при этом наблюдается максимум при $n=1$, однако в случае низкотемпературного монослоя $\varphi_{\max }=4.95 \mathrm{eV}$, затем $\varphi$ плавно падает до $\varphi=4.85 \mathrm{eV}$, соответствующей среднему значению $\varphi$ для $\mathrm{Si}$ при покрытии $n \geq 2$, тогда, как в случае поверхностного силицида, величина $\varphi_{\max }=4.95 \mathrm{eV}$ далее не меняется с ростом покрытия, так как весь сверхмонослойный кремний диффундирует в объем W вплоть до формирования объемного силицида $\mathrm{WSi}_{2}$ [11]. Подобную же картину наблюдали и авторы работы [2].

\section{2. Сверхмонослойные покрытия кремния}

При $T \geq 900 \mathrm{~K}$ уже наблюдается заметная диффузия атомов $\mathrm{Si}$ в объем W. Объемная диффузия действительно имеет место лишь при сверхмонослойных покрытиях, как это отмечалось и в работе [2], и процесс объемной диффузии приводит к образованию объемного силицида $\mathrm{WSi}_{2}$. Образование силицида происходит наиболее интенсивно в областях граней куба $\{100\}$, где параметры VCC решетки W, $a=0.316 \mathrm{~nm}$ и тетрагональная плотноупакованная решетка $\mathrm{WSi}_{2}, c=0.322 \mathrm{~nm}$ наиболее близко совпадают. В этом случае, также как и в случае адсорбции углерода на W, вначале формируется структура так называемого „ребристого кристалла“ [11], который можно охарактеризовать как первую стадию 

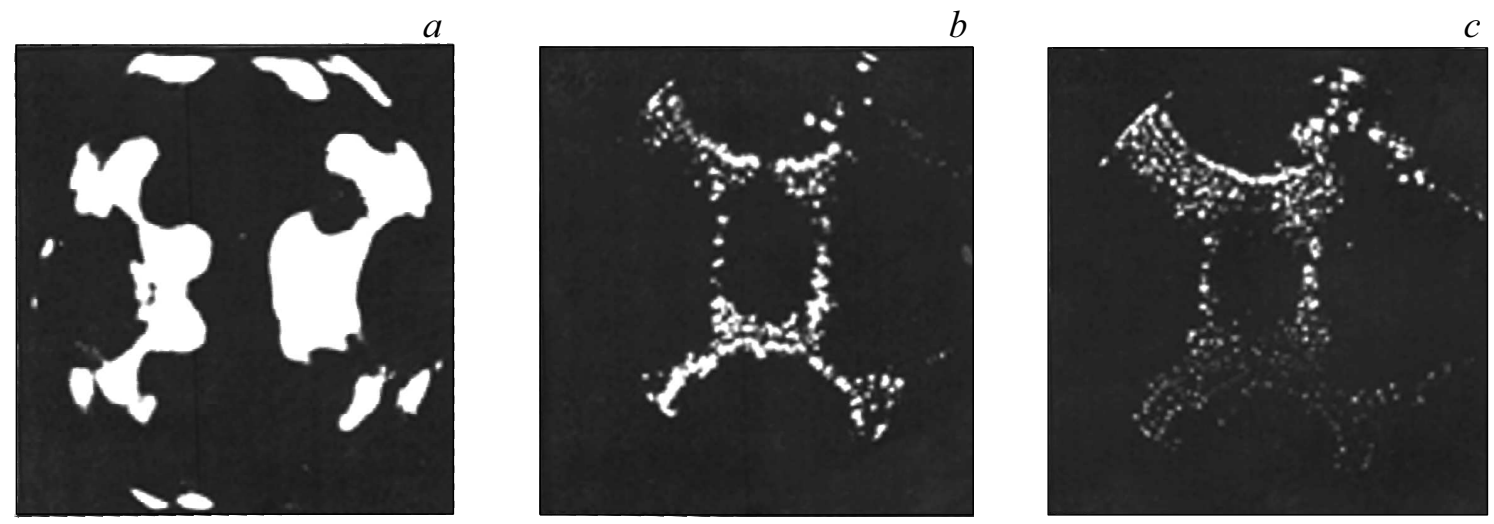

Pис. 3. Полевые электронные $(a)$ и ионные $(b, c)$ изображения поверхности в процессе полевого испарения объемного силицида $\mathrm{WSi}_{2}$ при $T_{s}=77 \mathrm{~K} . a-T_{s}=1200 \mathrm{~K}, n=3 ; b-U=17 \mathrm{kV}$ (изображающий газ - неон); $c-U=19 \mathrm{kV}$ (изображающий газ - неон).

силицидообразования $\mathrm{W}$ поскольку ОЦК решетка $\mathrm{W}$ не может скачком перестроится в $\mathrm{HCP-решетку} \mathrm{WSi}_{2}$. Полевое электронное изображение поверхности объемного силицида $\mathrm{WSi}_{2}$ показано на рис. 3, $a$. Силицид $\mathrm{WSi}_{2}$ удобно получать, сконденсировав предварительно несколько монослоев $\mathrm{Si}$, при комнатной $T_{s}$, а затем кратковременно прогреть эмиттер при $T_{s}=1000-1300 \mathrm{~K}$. При этом если долго выдерживать структуру $\mathrm{WSi}_{2}$ при $T=1300 \mathrm{~K}$, то объемный силицид растворится, и на поверхности будет наблюдаться картина поверхностного силицида, который всегда предшествует образованию $\mathrm{WSi}_{2}$ при напылении $\mathrm{Si}$ и всегда предшествует получению чистого $\mathrm{W}$ при прогреве объемного силицида. На рис. 3, $b, c$ показаны полевые ионные изображения поверхности силицида, который был получен конденсацией $n=5$ при $T_{s}=1200 \mathrm{~K}$ с разрешением, близким к атомарному. Полевое испарение поверхности силицида показывает наличие узких ребер моноатомной ширины в областях центральной грани $\{110\}$, а в областях $\{100\}$, где толщина слоя силицида больше, можно насчитать 5 моноатомных ступеней.

С помощью графика Аррениуса для скорости диффузии $\lg v=f(1 / T)$ были определены энергия активации объемной диффузии $\mathrm{Si}$, подобный график дал величину энергии $Q_{\text {dif }}=2.85-0.05 \mathrm{eV}$ и предэкспоненциальный множитель $\tau_{0}=3 \cdot 10^{-10} \mathrm{~s}$. Близкую по значению величину $Q=3.0-3.1 \mathrm{eV}$ получили и авторы работы [2], но в предположении изначально принятого „теоретического“ значения величины предэкспоненциального множителя для процесса поверхностной диффузии $\tau_{0} \sim 10^{-13} \mathrm{~s}$, однако подобная величина предэкспоненты наблюдается далеко не всегда (результат настоящей работы - еще одно тому подтверждение), поэтому пользоваться экспериментально определяемой величиной $\tau_{0}$, на наш взгляд, все же предпочтительнее. Метастабильный характер слоя $\mathrm{WSi}_{2}$, выросший в приповерхностной зоне острийного эмиттера, подтверждается тем обстоятельством, что количество сконденсированных монослоев $\mathrm{Si}$, кото- рое необходимо для образования $\mathrm{WSi}_{2}$, резко возрастает с ростом $T$ острия. Если при $T_{s}=900 \mathrm{~K}$ достаточно уже сконденсировать всего только $n=1.2$ монослоя для получения начальной стадии образования $\mathrm{WSi}_{2}$, то в случае роста $T_{s}$ до $1300 \mathrm{~K}$ для этого необходимо уже более 50 монослоев, поскольку объемная диффузия резко понижает концентрацию атомов $\mathrm{Si}$ в приповерхностной области $\mathrm{W}$, и эта концентрация оказывается ниже предельной растворимости $\mathrm{Si}$ в матрице $W$.

\section{3. Термическая стабильность и десорбция слоев Si}

При температурах $T_{s}>1500 \mathrm{~K}$ начинается процесс термической десорбции $\mathrm{Si}$ с поверхности. Десорбцию монослойного покрытия демонстрируют эмиссионные картины рис. 4, изменение этих картин происходит как бы обратно случаю конденсации. Вначале, при относительно низких $T_{s}=1600 \cdot 1750 \mathrm{~K}$ (рис. 4, $a, b$ ) вновь возникают темные области граней $\{111\}$, грани $\{013\}$ исчезают, но вокруг граней $\{001\}$ формируются грани типа $\{113\}$, заканчивается эта стадия десорбции формированием эмиссионной картины, похожей на квазичистый $\mathrm{W}$ (рис. $4, d$ ). Рост $T_{s}$ до $2100 \mathrm{~K}$ приводит к полной десорбции $\mathrm{Si}$ с поверхности $\mathrm{W}$ (рис. 4,f). Графики Аррениуса для скорости десорбции показали, что наблюдаются две стадии десорбции - низкотемпературная в интервале $T_{s}=1600-1800 \mathrm{~K}$ и высокотемпературная в интервале $T_{s}=1850-2100 \mathrm{~K}$. Приводить экспериментальные графики Аррениуса для определения $Q_{\operatorname{des}}$ в виде двух прямых линий в координатах $\lg v=f(1 / T)$ необходимости видимо нет, но следует отметить только, что для первой стадии десорбции величина энергии активации десорбции $Q_{\mathrm{des}}=5.18 \pm 0.02 \mathrm{eV}$, при этом предэкспоненциальный множитель равен $\tau_{0}=6 \cdot 10^{-16} \mathrm{sec}$, а для второй стадии величина $Q_{\mathrm{des}}=5.82 \pm 0.04 \mathrm{eV}$ и $\tau_{0}=4 \cdot 10^{-13} \mathrm{~s}$. То, что на первой стадии десорбции изменения происходят в основном в областях граней $\{111\}$ не значит, конечно, что десорбция происходит именно из 


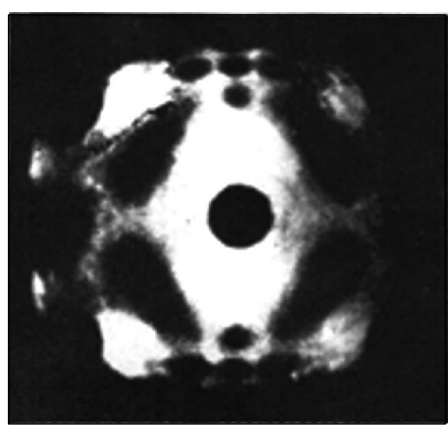

$d$

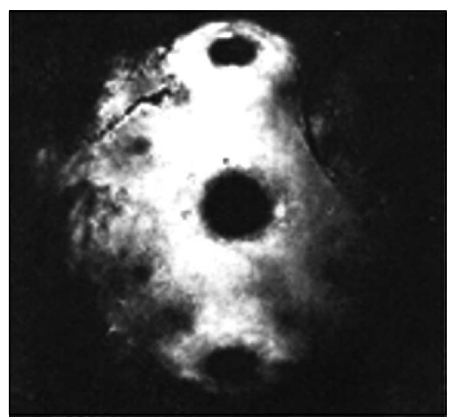

$b$

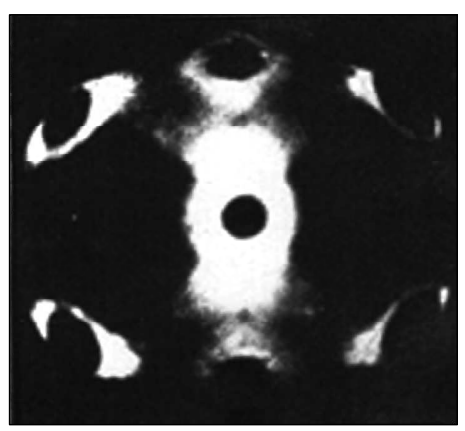

$e$

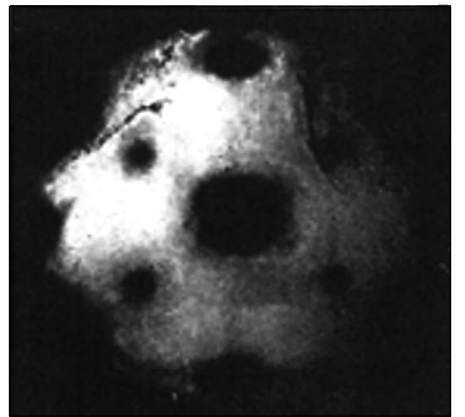

$c$
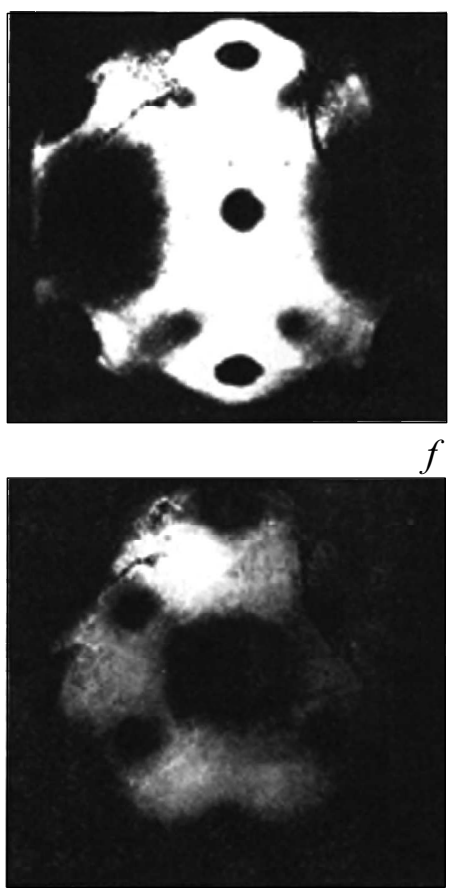

Рис. 4. Полевые электронные изображения поверхности в процессе десорбции поверхностного силицида W: $a-$ исходный поверхностный силицид; $b-$ после прогрева эмиттера при $T_{s}=1600 \mathrm{~K} ; c-$ при $T_{s}=1715 \mathrm{~K} ; d-$ при $T_{s}=1830 \mathrm{~K} ; e-$ при $T_{s}=1900 \mathrm{~K} ; f$ - при $T_{s}=2100 \mathrm{~K}$.

этих областей. В условиях миграционного равновесия на поверхности, когда логарифмы концентраций адсорбата на разных гранях пропорциональны теплотам испарения с этих граней, десорбция происходит со всей поверхности. Наличие же двух стадий десорбции говорит о том, что на поверхности W при покрытиях, близких к монослою, существуют адсорбционные места для адатомов $\mathrm{Si}$ с большей или меньшей связью с поверхностью W, т. е. сильно и слабосвязанные места. Причем при монослойном покрытии поверхностного силицида объемная диффузия не происходит вообще, этот факт также обнаружили авторы работы [2] с помощью методики ожеспектроскопии. На первый взгляд этот факт кажется несколько удивительным - отсутствие объемной диффузии при наличии огромного градиента концентрации (на поверхности концентрация $n=10^{15} \mathrm{at} / \mathrm{cm}^{2}$, а во втором слое $\mathrm{W}$ на расстоянии $0.3 \mathrm{~nm}$ концентрация $n=0$ ) и это при достаточно высоких температурах $T_{s} \sim 1400 \mathrm{~K}$. При этом атомы $\mathrm{Si}$, оказавшиеся во втором слое, „тонут в объем W уже при $T_{s} \geq 900 \mathrm{~K}$.

Эксперименты по изучению термической стабильности поверхностного силицида показали, что при длительном (десятки минут) прогреве его при $T \leq 1300 \mathrm{~K}$ никакого изменения эмиссионной картины, а также и изменения работы выхода поверхности не происходит. Рост $T_{s}$ до $1370 \mathrm{~K}$ (всего на 1500 ниже $T$ начала заметной десорбции) вызывает после длительного прогрева в течение десятков минут падение исходной $\varphi$ всего на $\Delta \varphi=0.10-0.12 \mathrm{eV}$ и очень слабое изменение эмиссионной картины поверхности.

Таким образом, в случае конденсации Si на поверхности W действительно образуется сильносвязанное состояние поверхностного силицида W. Формирование этого состояния заканчивается тогда, когда все свободные связи атомов на поверхности оказываются насыщенными, a это происходит при достижении состояния геометрического монослоя при поверхностной концентрации $n \sim 1 \cdot 10^{15} \mathrm{at} / \mathrm{cm}^{2}$. Энергия активации объемной диффузии для атомов из этого состояния оказывается близкой, а возможно даже и большей теплоты десорбции атомов $\mathrm{Si}$ с поверхности W, поэтому атомы $\mathrm{Si}$ из состояния поверхностного силицида участия в объемной диффузии не принимают. Надо отметить, что подобные сильно и слабосвязанные состояния наблюдались и ранее на других адсорбционных системах. Так, в диссертационной работе Джалилова [12] наблюдалось в случае адсорбции кислорода на тантале Та и ниобие $\mathrm{Nb}$ также два состояния для атомов $\mathrm{O}$ - сильно и слабосвязанные, при этом эффект был даже сильнее, чем для системы $\mathrm{Si}-\mathrm{W}$. Кислород из сильносвязанного состояния первого монослоя не участвовал в объемной диффузии, а только десорбировался с поверхности Та при $T \geq 2500 \mathrm{~K}$, тогда как атомы О из слабосвязанного состояния второго слоя диффундировали в объем Та уже при $T \geq 400 \mathrm{~K}$.

Можно при этом предположить, что адатомы Si диффундируют в объем W не по обычному прыжковому механизму, а по механизму обмена или замещения. 
Суть подобного механизма в данном случае состоит в том, что адатом из второго слоя $\mathrm{Si}$ ныряет в первый слой поверхностного силицида, занимает там место и выпихивает атом из первого слоя в объем W. Подобного рода механизм впервые был экспериментально обнаружен Эрлихом и Ригли [13] много лет назад с помощью полевой ионной микроскопии и теоретически обоснован Фейбельманом [14], который показал, что для случая диффузии одиночного адатома $\mathrm{Al}$ на грани $\{100\} \mathrm{Al}$ энергия активации объемной диффузии по обменному механизму оказывается на $1 / 3$ меньше чем энергия активации диффузии по обычному классическому прыжковому механизму. Подобный механизм диффузии был впоследствии подтвержден экспериментами с помощью полевой ионной микроскопии и атомного зонда [15-16]. Однако в работе [17] было показано, что хотя обменный механизм и требует меньшей энергии активации, но он реализуется не всегда. Такой механизм требует согласованного движения поверхностного атома и атома подложки, а для этого поверхностному атому необходимо быть в адсорбированном положении определенное время. Вследствие этого вместо обменного механизма часто реализуется прыжковый, хотя он и требует большей энергии активации.

\section{Заключение}

1. Таким образом, кремний, адсорбированный на поверхности вольфрама может быть структурно в трех состояниях - аморфный слой при низких $T_{s}$, низкотемпературный монослой, примерно повторяющий структуру поверхности $\mathrm{W}$ при более высоких $T_{s}$ и при самых высоких $T_{s}$ - поверхностный силицид - монослой, связанный с реконструкцией поверхности подложки и появления на ней новых граней.

2. Главный вывод работы состоит в том, что на одной и той же исходной поверхности $\mathrm{W}$ при одной и той же ее температуре $T_{s}$ и в случае конденсации одного и того же адсорбата $\mathrm{Si}$ могут реализовываться различные механизмы роста, приводящие к совершенно различным конечным результатам в зависимости от того, в каком состоянии находится исходная поверхность покрытой монослоем адсорбата Si подложки W. Собственные кристаллиты Si на W можно получить при конденсации $\mathrm{Si}$ как начиная с 3 монослоев, так и начиная примерно с 300 монослоев в зависимости от состояния поверхности $\mathrm{W}$, покрытой Si.

3. На поверхности W адатомы Si могут существовать в двух состояниях - сильно и слабосвязанном. Состояние поверхностного силицида является сильносвязанным и адатомы из такого состояния не принимают участия в объемной диффузии, поскольку энергия активации такого процесса может быть близкой, а, возможно, даже и больше энергии десорбции $\mathrm{Si}$ с поверхности W.

4. Объемная диффузия осуществляется атомами второго слоя адсорбата $\mathrm{Si}$ скорее всего не по прыжковому механизму диффузии, а по механизму обмена, когда адатом второго слоя занимает место в первом слое, выпихивает адатом первого слоя в объем W.

\section{Конфликт интересов}

Автор заявляет, что у него нет конфликта интересов.

\section{Список литературы}

[1] Flaim T.A., Ownby P.D. // Surf. Sci. 1972. Vol. 32. N 3. P. 519-526.

[2] Gall N.R., Rutkov E.V., Tontegode A.Ya. // Thin Solid Films. 1995. Vol. 266. P. 229-238.

[3] Tsong T.T., Wang S.C., Liu H.F. // Journ. Vac. Sci. Tech. 1983. B1. P. 915-922.

[4] Tsong T.T. // Surf. Sci. Rep. 1988. Vol. 8. N 3/4. P. 127-207.

[5] Nishikava O., Tomori M., Iwawaki F. // Surf. Sci. 1992. Vol. 266. P. 204-213.

[6] Svec M., Hapala P., M. Vondrecek M., Merino P., Banca Rey M., Mutombo P., Polyak Y., Chab V., Yelinec P. // Phys. Rev. 2014. B 89. P. 291912.

[7] Aufrei B., Kara A., Vizzini S., Oughaddou H., Leandry C., Ealet B., Lay G. // Appl. Phys. Lett. 2016. Vol. 96. P. 183102.

[8] Голубев О.Л., Конторович Е.Л., Шредник В.Н. // ЖТФ. 1996. Т. 66. Вып. 3. С. 88-96.

[9] Голубев О.Л. // ЖТФ. 2011. Т. 81. Вып. 6. С. 113-119.

[10] Fowler R.H., Nordheim L. // Proc. Roy. Soc. 1928. Vol. 119. A781. P. 173-181.

[11] Голубев О.Л. // Письма в ЖТФ. 2018. Т. 44. Вып. 23. C. $9-15$.

[12] Авторефб. канд. дис. Джалилов С.Т. Исследование взаимодействия кислорода с тугоплавкими металлами (W, Ta, Nb, Ir) методом электронностимулированной десорбции. Л. ФТИ им. А.Ф. Иоффе АН СССР. 1977. 150 с.

[13] Wrigley J.D., Ehrlich G. // Phys. Rev. Lett. 1980. Vol. 44. N 10. P. 661-663.

[14] Feibelman P.J. // Phys. Rev. Lett. 1990. Vol. 65. N 6. P. 729 732.

[15] Chonling Chen, Tsong T.T. // Phys. Rev. Lett. 1990. Vol. 64. N 26. P. 3147-3150.

[16] Kellog G.L., Feibelman P.J. // Phys. Rev. Lett. 1990. Vol. 64. N 26. P. 3143-3146.

[16] Kellog G.L. // Surf. Sci. 1992. Vol. 266. P. 18-23. 